\title{
Congenital absence of posteromedial papillary muscle and anterior mitral leaflet chordae: The use of three-dimensional echocardiography and approach in complex pediatric mitral valve disease
}

\author{
Christopher W. Baird, MD, ${ }^{\mathrm{a}}$ A. Resai Bengur, MD, ${ }^{\mathrm{b}}$ Andrew Bensky, MD, ${ }^{\mathrm{b}}$ and Larry T. Watts, MD, ${ }^{\mathrm{a}}$ \\ Charlotte, NC
}

Complete congenital absence of a papillary muscle is in itself a rare phenomenon. Usually, when a papillary muscle

\footnotetext{
From the Levine Children's Hospital, Carolina's Healthcare System, and The Sanger Clinic, Departments of Pediatric Cardiovascular and Thoracic Surgery ${ }^{\mathrm{a}}$ and Cardiology, ${ }^{\mathrm{b}}$ Charlotte, NC.

Disclosures: None.

Received for publication Sept 16, 2008; revisions received Feb 16, 2009; accepted for publication March 7, 2009; available ahead of print May 18, 2009.

Address for reprints: Christopher W. Baird, MD, The Sanger Clinic, 1001 Blythe Blvd,

Suite 300, Charlotte, NC 28211 (E-mail: bairdc1@gmail.com).

J Thorac Cardiovasc Surg 2010;139:e75-7

$0022-5223 / \$ 36.00$

Copyright $@ 2010$ by The American Association for Thoracic Surgery

doi:10.1016/j.jtcvs.2009.03.006
}

is absent there are chordae that arise from a single papillary muscle inserting into the leaflets (ie, parachute mitral valve) ${ }^{1}$ or chordae that arise directly from the ventricular wall. ${ }^{2}$ Complete chordal papillary muscle agenesis to certain leaflet segments is extremely uncommon. We present a case of severe mitral regurgitation resulting from anterior leaflet prolapse with no chordal attachments and absence of a posteromedial papillary muscle chordal apparatus.

A 6-year-old girl received a diagnosis of mitral regurgitation at 3 years of age. This progressed to severe mitral regurgitation by the age of 6 years, and she was therefore referred for surgical evaluation. Two- and 3-dimensional echocardiography (transthoracic, transesophageal, and epicardial)
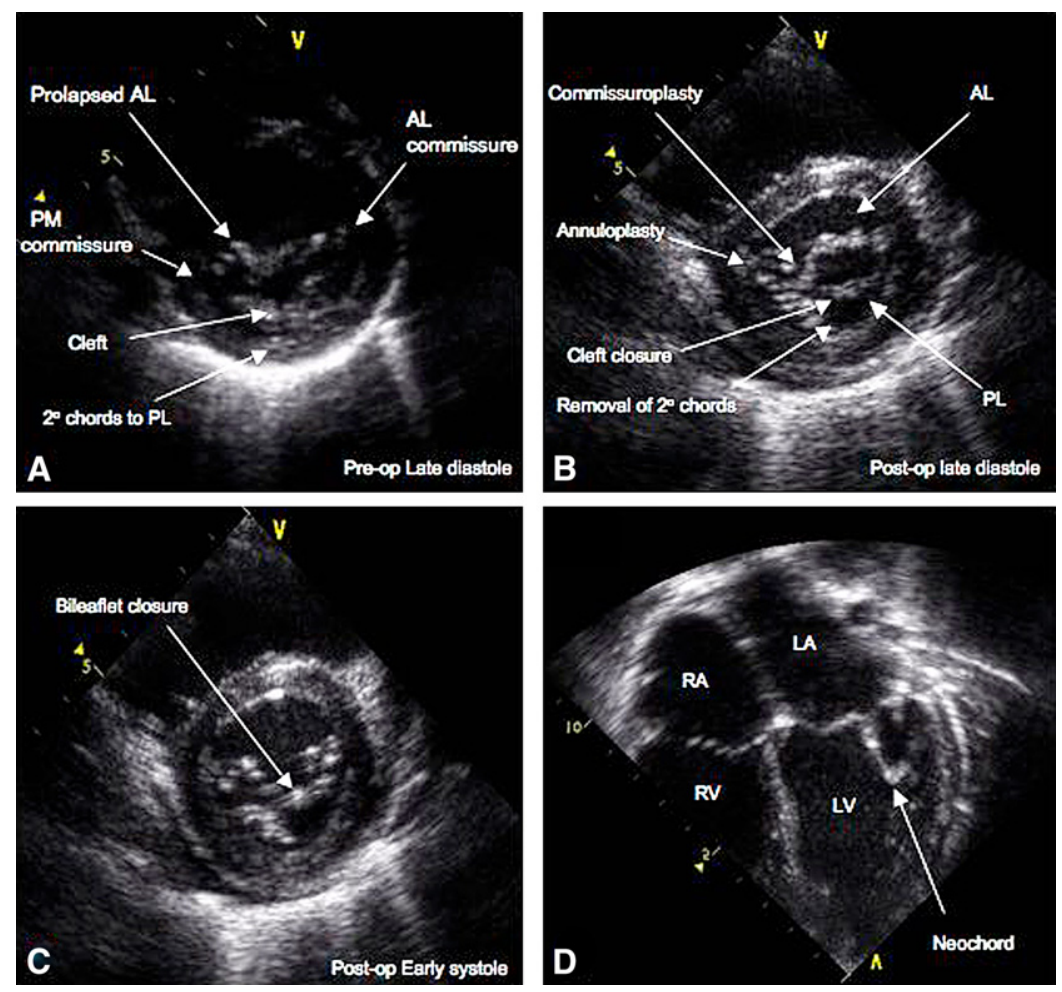

FIGURE 1. Preoperative and postoperative transthoracic echocardiograms (TTE). A, Preoperative TTE with short-axis view from the ventricle in late diastole. Primary disease is shown, including a prolapsed anterior leaflet, a cleft in the anterior leaflet, secondary chordae tethering the posterior leaflet, and a rudimentary posteriomedial commisure. B, Postoperative TTE, short-axis view from the ventricle, showing the areas of repair. These include the commissuroplasties and annuloplasties, closure of anterior leaflet cleft, and division of secondary chordae attached to the posterior leaflet. C, Postoperative TTE, shortaxis view from ventricle, showing anterior and posterior leaflet apposition without leaflet prolapse. D, Postoperative TTE, 4-chamber view, showing the neochorda from the posteriomedial papillary muscle remnant attaching to the anterior mitral valve leaflet. 
were used to delineate mitral valve anatomy (Figure 1). The pathologic condition consisted of severe mitral regurgitation resulting from an absent posteromedial papillary muscle, an absent chordal apparatus to the central anterior leaflet, and a severely tethered posterior leaflet toward the posteromedial commissure. Embryologically, this was probably a cleft in the anterior leaflet with a rudimentary posteromedial commissure. After bicaval cannulation, cardiopulmonary bypass, and hypothermic $\left(25^{\circ} \mathrm{C}\right)$ fibrillatory arrest, the mitral valve was viewed via a transseptal approach through the right atrium. Intraoperative examination revealed a remnant of what appeared to be posteromedial papillary muscle matted to the lateral ventricular wall. There were no chordal structures attaching to the central portion of the anterior leaflet, which had a cleft and a tethered posterior leaflet owing to secondary chordae (Figure 2). With the aid of hypothermic spontaneous ventricular fibrillation, initial inspection and repair consisted of division of the secondary chordae tethering the posterior leaflet, anterolateral and posteromedial commissuroplasties, and closure of the anterior leaflet cleft. Then, under cardioplegic arrest, a neochord was created with 5-0 polytetrafluoroethylene from the lateral ventricular wall and attached to the anterior leaflet as described by Duran and Pekar ${ }^{3}$ and Boon and associates, ${ }^{4}$ as well as figure-of-8 suture anterolateral and posteromedial annuloplasties. Postoperative transthoracic echocardiography (Figure 1, B, C, and $D$ ) revealed no mitral stenosis or regurgitation, ventricular function was within normal limits, recovery was uneventful, and the patient was discharged home on postoperative day 4. Follow-up at 1 year revealed no mitral stenosis or regurgitation.

\section{COMMENT}

Most congenital abnormalities of the mitral valve papillary muscles are associated with a single papillary muscle or "parachute mitral valve" and absence of the anterolateral papillary muscle. Carpentier and associates ${ }^{2}$ reported a case of posterolateral papillary muscle absence with chordae arising from the ventricular free wall. Herein, we report a unique case of posteromedial papillary muscle and chordal agenesis with no attachments to the central and posteromedial anterior leaflets.

This child had a complex mitral valve abnormality involving anterior and posterior leaflets. Most significant was the absence of a chordal apparatus to the anterior leaflet with rudimentary evidence of a posteromedial papillary muscle. The posterior leaflet was compensated with secondary chordae limiting posterior leaflet prolapse, but the anterior leaflet had no compensatory mechanisms.

del Nido (personal communication, 2008) developed a systematic approach using 2- and 3-dimensional echocardiography for preoperative and intraoperative assessment allowing an accurate and, more important, aggressive surgical approach toward complicated mitral valve disease and its re-

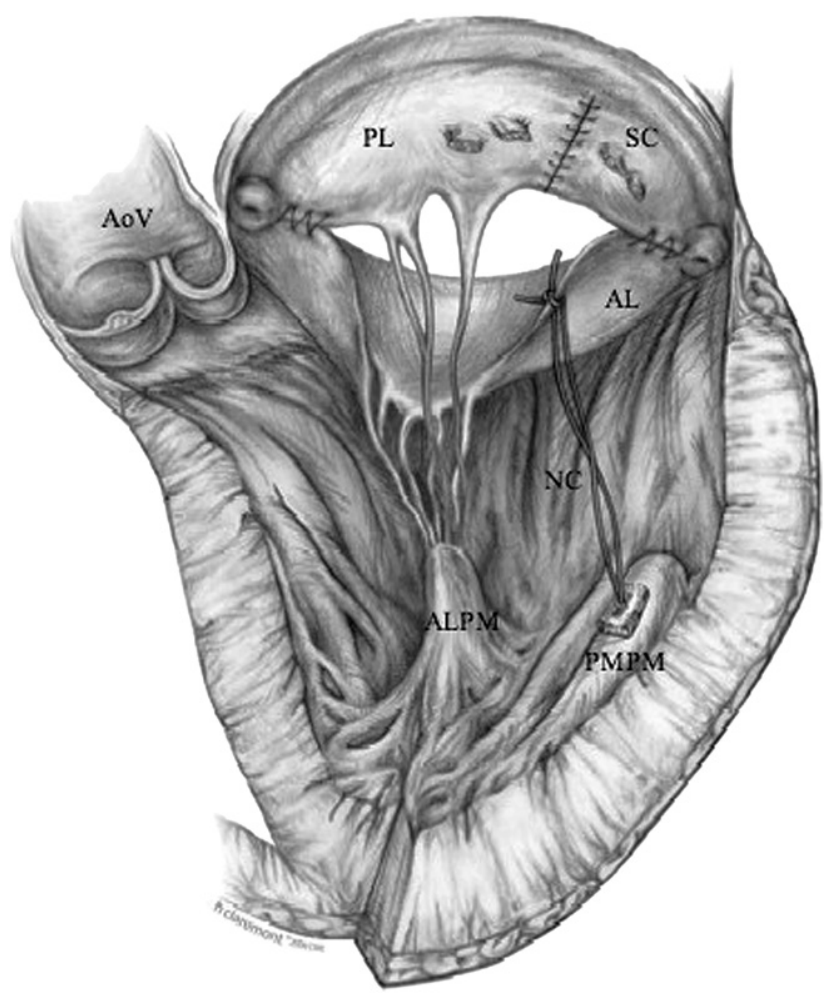

FIGURE 2. Schematic of postoperative repair representing posteromedial and anterolateral comissuroplasties, figure-of- 8 suture posteromedial and anterolateral annuloplasties, anterior leaflet cleft closure, division of secondary chordae restricting the posterior leaflet, and creation of a neochorda from the rudimentary posteromedial papillary muscle to the free edge of the anterior leaflet. $A L$, Anterior leaflet; $P L$, posterior leaflet; $R A$, right atrium; $R V$, right ventricle; $L A$, left atrium; $L V$, left ventricle.

pair. ${ }^{5}$ For example, if echocardiography revealed significant secondary and/or tertiary chordae and one could not visualize them by direct views through the mitral orifice, one might elect to take down the posterior leaflet for better visualization.

Complex congenital mitral valve disease often requires more time for repair; thus, methods of cardiopulmonary bypass and myocardial protection are important determinants of optimal outcomes. del Nido routinely uses spontaneous hypothermic fibrillatory arrest, inasmuch as it provides an excellent alternative to complete cardioplegic arrest in complex mitral valve disease. When ventricular fibrillation is allowed to spontaneously occur under hypothermic conditions $\left(25^{\circ} \mathrm{C}-28^{\circ} \mathrm{C}\right)$, spontaneous cardioversion is unlikely to occur until rewarming. Use of the ascending aortic cardioplegia site for continuous venting can minimize concerns of air emboli. Fibrillation allows continued myocardial perfusion, maintains myocardial tonus during repair, and provides more physiologic testing of the mitral valve while significantly minimizing crossclamp and ischemic times. We still often use a short period of single-dose cardioplegic arrest 
for portions of the repair (ie, annuloplasties and tightening of neochordae).

Complete absence of chordal structures associated with leaflet prolapse, such as seen with a cleft in the anterior mitral leaflet, creates a difficult problem for short- and longterm outcomes in pediatric patients. Routine maneuvers such as commissuroplasties and annuloplasties are not always effective. More complex techniques including creating neochordae ${ }^{3}$ or creating a double-orifice mitral valve (ie, the Alfieri repair ${ }^{6}$ ) can often provide effective short-term results. Alfieri's initial description ${ }^{6}$ of edge-to-edge leaflet approximation for adults with severe regurgitation has proven excellent results and should be considered in children. However, the creation of neochordae $e^{3,4}$ for significant prolapse provides a more natural effect and less potential for mitral stenosis; if necessary, as the child grows, the neochordae can be replaced without valve replacement.

Using preoperative and intraoperative 3- and 2-dimensional echocardiography, one is able to optimally plan an approach and the repair of complicated mitral valve abnormalities. Furthermore, as an alternative to complete cardioplegic arrest, spontaneously induced hypothermic ventricular fibrillation allows one to inspect and perform much of the repair under more physiologic conditions without significantly compromising myocardial function.

I would like to thank Dr Pedro del Nido for his continuing contributions to the field of congenital valve disease and repair. Dr del Nido at Boston Children's Hospital developed many of the concepts used herein, passing them to me during my time in Boston. I would also like to thank Heather Claremont for help with the illustrations.

\section{References}

1. Shone JD, Sellers RD, Anderson RC, Adams P Jr, Lillehei CW, Edwards JE. The developmental complex of "parachute mitral valve," supravalvular ring of left atrium, subaortic stenosis, and coarctation of aorta. Am J Cardiol. 1963;11: 714-25.

2. Carpentier A, Branchini B, Cour JC, Asfaou E, Villani M, Deloche A, et al. Congenital malformations of the mitral valve in children: pathology and surgical treatment. J Thorac Cardiovasc Surg. 1976;72:854-66.

3. Duran CM, Pekar F. Techniques for ensuring the correct length of new mitral chords. J Heart Valve Dis. 2003;12:156-61.

4. Boon R, Hazekamp M, Hoohenkerk G, Rijlaarsdam M, Schoof P, Koolbergen D et al. Artificial chordae for pediatric mitral and tricuspid valve repair. Eur J Cardiothorac Surg. 2007;32:143-8.

5. Cannon JW, Stoll JA, Salgo IS, Knowles HB, Howe RD, Dupont PE, et al. Realtime three-dimensional ultrasound for guiding surgical tasks. Comput Aided Surg. 2003;8:82-90

6. Fucci C, Sandrelli L, Pardini A, Torracca L, Ferrari M, Alfieri O. Improved results with mitral valve repair using new surgical techniques. Eur J Cardiothorac Surg. 1995;9:621-6; discussion 626-7.

\title{
Iatrogenic phrenic nerve injury during thymectomy: The extent of the problem
}

\author{
Michele Salati, MD, ${ }^{\mathrm{a}}$ Giuseppe Cardillo, MD, FETCS, ${ }^{\mathrm{b}}$ Luigi Carbone, MD, ${ }^{\mathrm{b}}$ Federico Rea, MD, ${ }^{\mathrm{c}}$ \\ Giuseppe Marulli, MD, ${ }^{\mathrm{c}}$ Alessandro Brunelli, MD, ${ }^{\mathrm{a}}$ Luca Voltolini, MD, ${ }^{\mathrm{d}}$ Giuseppe Gotti, MD, ${ }^{\mathrm{d}}$ and \\ Gaetano Rocco, MD, FRCSEd, ${ }^{\mathrm{e}}$ Ancona, Rome, Padua, Siena, and Naples, Italy
}

If a thymic neoplasm infiltrates both the phrenic nerves, it is mandatory to spare one of them to reduce respiratory function impairment. ${ }^{1}$ To our knowledge, there is no information in the

\footnotetext{
From the Unit of Thoracic Surgery, ${ }^{a}$ Umberto I Regional Hospital, Ancona, Italy; the Unit of Thoracic Surgery, ${ }^{b}$ Azienda Ospedaliera San Camillo Forlanini, Rome, Italy; the Department of Cardiologic, Thoracic and Vascular Sciences, Division of Thoracic Surgery, ${ }^{c}$ University of Padova, Padua, Italy; the Thoracic Surgery Unit, ${ }^{\mathrm{d}}$ University Hospital of Siena, Siena, Italy; and the National Cancer Institute, ${ }^{\mathrm{e}}$ Pascale Foundation, Naples, Italy.

Disclosures: None.

Received for publication April 23, 2008; revisions received May 20, 2008; accepted for publication June 10, 2008; available ahead of print June 1, 2009.

Address for reprints: Michele Salati, MD, Via A. De Gasperi 17/c, 60020 Offagna, Italy (E-mail: michelesalati@hotmail.com).

J Thorac Cardiovasc Surg 2010;139:e77-8

$0022-5223 / \$ 36.00$

Copyright (C) 2010 by The American Association for Thoracic Surgery

doi:10.1016/j.jtcvs.2008.06.051
}

literature regarding the incidence of unilateral phrenic nerve resection for radically treated thymic neoplasms (Figure 1).

\section{CLINICAL SUMMARY}

In January 2007 we created a multi-institutional diseasespecific database. We retrospectively gathered data in an electronic format from 5 Italian thoracic surgery units, each of them performing at least 8 thymectomies per year, irrespective of the surgical approach.

We enrolled 183 patients ( 93 female and 90 male patients; median age, 56.6 years) from January 2000 to December 2006 who were operated on for thymoma or thymic carcinoma. Patients with a preoperative diagnosis of generalized myasthenia or other neuromuscular syndromes were excluded.

Two of the following criteria should be verified to define the phrenic nerve as injured after the operation: (1) description of the phrenic nerve resection within the operating 